\title{
https://doi.org/10.48009/1_iis_2006_119-123 \\ THE MIS CAPSTONE COURSE: AN ACTIVE LEARNING APPROACH
}

\author{
Marzie Astani, Winona State University, mastani@winona.edu
}

\begin{abstract}
This paper describes the implementation of an active learning approach in an MIS capstone course that allows students to actively participate in learning about the key issues that CIOs face when managing information resources. The objective of this approach was to help students to develop an understanding of IS management issues and the role of CIOs in organizations. In an attempt to achieve this objective, students were required to interview local/regional CIOs face-to-face. The focus of this paper is to present this approach of learning, the students' findings based on their interviews, and the students' feedback on this learning experience.
\end{abstract}

Keywords: CIO's Role, IS Management Issues, Active Learning, Capstone Course

\section{INTRODUCTION}

The rapidly changing technology along with a turbulent business environment has made management of information resources complex. In this environment chief information officers (CIOs) need to stay current in technology, and know the business of their organization as well, in order to contribute to the firm's strategic planning. These are challenging times for chief information officers of companies, indeed.

The changing role of CIOs in organizations and the issues they face in managing information systems departments are discussed in the MIS capstone course. Although students read about the IS issues and the role of the CIO; nevertheless, it is difficult for them to comprehend these challenges. For example, students need to develop a good understanding of the strategies that CIOs implement to provide necessary services with the limited IT budget. To help students understand the nature and complexity of the issues in IT management, a method of teaching/learning was used that required students' active participation. The students were guided through a process that led them to learn and better understand the issues CIOs deal with in organizations. Further, students learned how the issues are prioritized by CIOs.
In the next section, some of the key issues in IT management will be discussed, followed by the methodology used in the MIS capstone course and the analysis of the data collected by students. In the conclusions section, student feedback related to their experience in the active learning is presented.

\section{CRITICAL ISSUES IN INFORMATION SYSTEMS MANAGEMENT}

Top IT managers face a vast number of issues and challenges on a day-to day basis when managing information resources in organizations. Several of these key issues are discussed below.

There are several IT activities that are critical for IS organizations. According to the literature, the top three core activities are strategic alignment of business and technology, delivery of high quality IS services at low cost, and developing and implementing IT architecture [1, 5, 8, 9, 10, 13, 15]. Several other factors are necessary conditions to the above core IS activities. For example, the critical issue of business and IS alignment requires top management support and a good relationship between the IT department and users within the organization $[5,9,10,15]$. Top management commitment is essential in developing IT-related competencies [12]. Furthermore, the CEO's commitment and involvement has been strongly linked to the overall success of IS planning effort [8].

In addition, communication between the IS department, top management, and user community is critical for the alignment effort [3]. To facilitate this communication, the cultural gap between the IT community and the rest of the organization [16] needs to be bridged. Success of the IS department depends on the relevant strategy being wellarticulated by CIOs [11]. Therefore, CIOs need to create more interactions between the IS community and the rest of the organization and raise the awareness of how IT relates to business issues [2] if strategies are to be aligned. As Boynton et al. [6] state, the effective application of IT depends on how well the firm's IT manager and line managers are linked together through the exchange of IT-related knowledge and processes. 
Another key IS management challenge for CIOs is keeping IT staff's skill sets current. Organizations must build and sustain a strong IT staff and a reusable technology base. IT staffs need to be critical thinkers, result oriented, possess technical and business skills, and have interpersonal skills [17]. Furthermore, CIOs need to establish realistic standards and a system to continuously determine the IT staff's performance effectiveness [12].

IT budget allocation, which to some degree reflects top management's commitment and attitude towards IT, is another issue. Insufficient IT resources could be the source of numerous problems such as poor IT staff skill sets and quality of services [14] that many CIOs face. With the limited IT budget, the IT governance structure becomes very important since IT investment and expenditures have become so large and diverse that management has to find a way to bring order to all decision making [13].

One of the strategies that has been used to provide high quality IT services at a reduced cost is outsourcing $[9,12]$. A CIO needs to decide whether it is cost-effective to outsource some of the noncore IS functions and, if so, which should be selected. Careful scrutiny needs to be enforced in IS functions outsourcing. However, outsourcing of some IS functions may be the source of other IT issues such as service quality, information resource security, and contract management [8]. Nevertheless, there are inherent risks involved in IT operations and development, such as users being uncertain about their IT needs, risk involved in new technology, business requirements change, and implementation, whether the function is outsourced or not.

Information systems security is one of the main challenges for CIOs. It is critical that the top IT manager establishes a set of security policies and enforces them in the organization. The growth of the Internet and e-commerce has brought security issues to the forefront [7]. Protecting organization's assets is one of the main responsibilities of the CIO.

In addition to all the above issues, there are many other IS management issues that CIOs are facing, such as organizational information systems integration, redesigning business processes using IT, managing legacy systems, new technology implementations such as radio frequency identification (RFID), and user training. As Booth and Philip [5] put it, the complexity of CIO's role calls for a highly unique blend of skills for any potential IS/IT manager.

\section{RESEARCH METHODOLOGY}

The above issues and the role of the CIO is the main focus of the MIS capstone course. Students need to understand how CIOs prioritize the issues on a dayto-day basis to find a balance in spending their efforts and a limited IS budget. Considering the complexity of these topics, the instructor needs to find a way to facilitate better learning and understanding. In the spring semester of 2005, in an attempt to achieve this objective, a method of experiential learning was implemented that called for students' active participation. The following describes the process used to facilitate active learning.

Students enrolled for the capstone course were told that they would be involved in a major project in addition to the usual course material. During the third week of the semester, the active learning process was initiated. This process involved six phases. All phases with related activities are presented below:

Phase I - Each student was required to search and select an appropriate research paper published in a scholarly journal, read and summarize the paper, and submit a list of issues in IT management based on the reading. The objective was for the students to develop an understanding about the IS management issues and be prepared for later activities. While individual students were going through this process, the instructor invited a number of local/regional organizations' CIOs to participate in this active learning project. The sample of organizations included financial, health services, and manufacturing firms.

Phase II - Pairs of students were assigned to work in groups for the rest of the project. Each individual student was required to meet and discuss his/her findings with the other group member. Each group was required to develop a combined list of IS management issues. At this time, each group was given the contact information of a local/regional CIO to arrange an interview session.

Phase III - All groups presented and discussed the summary of their papers and their findings about IS management issues in class. This was followed by a guided class discussion about the key issues to be included in the list for interviewing the CIOs. The outcome of the discussion was a final list of key IS management issues.

Phase IV - The instructor developed an interview questionnaire based on the key issues that were determined in class. Likert scale of 1-5 was used in 
the questionnaire (shown in the tables below.) The questionnaire also contained some general questions about each CIO's organization, such as the name and size of the firm.

Phase $V$ - The groups of students interviewed the CIOs face-to-face, recorded the findings, and tabulated the results.

Phase VI - Each group of students presented their findings in class along with a description of their own learning experience. Questions and discussion followed the presentations.

\section{RESULTS}

All groups' findings were accumulated and analyzed by the instructor. The final statistical analysis of the data was presented in class followed by a discussion of the results. The results were organized into three categories and are presented along with the related ratings in Tables 1, 2, and 3 . The following presents the discussion and interpretation of the results.

Table 1. CIOs' Ratings of the Importance of Key IS Management Issues

\begin{tabular}{lc}
\multicolumn{1}{c}{ IS Issues } & $\begin{array}{c}\text { Average } \\
\text { Rating* }\end{array}$ \\
\hline Strategic Alignment of IS and & 4.5 \\
Organization & 4.1 \\
Network Integration & 4.0 \\
Facilitating Business Process Redesign & 4.0 \\
IS Role in Organization & 3.7 \\
IS Strategic Plan & 3.7 \\
Building IS Infrastructure & 3.6 \\
Knowledge Management & 3.3 \\
Investing in IT & 1.8 \\
IS Outsourcing &
\end{tabular}

The first category of issues and ratings are presented in Table 1. The CIOs were asked to rate the importance of the issues based on their organizations' current situations, using the scale provided. As shown, for the most part the students' findings were consistent with those of the literature. However, there were some contradictions. For example, unlike the literature that emphasizes the importance of IT investment $[13,15]$, the CIOs involved in the project did not feel very strongly about the importance of this issue. The average rating for 'Investing in IT' was
3.3. Only fifty-three percent of the CIOs rated the importance of IT investment as high or very high (4 or 5). The result of another issue, IT outsourcing, was also inconsistent with the literature. As discussed in the literature, one of the top IS manager's challenge is providing high quality service at low cost, which is achieved by some organizations through IS outsourcing [9]. This issue received an average rating of 1.8 from the CIOs, indicating that they thought this issue has very little importance. Perhaps this could mean that the organizations were not involved in IT outsourcing, although one third of the firms in the sample are manufacturing companies.

The second set of interview questions and ratings are shown in Table 2. The CIOs were asked to rate the quality of their IS departments concerning some characteristics shown in Table 2 on the scale provided. The high ratings of the top four items in the table (average ratings between 4.2 - 4.3) reflects that the CIOs are confident about their departments' capability in providing high quality services and their staffs' skill sets. However, the average rating of 3.8 for the 'IS Department's Delivery' is not consistent with that result. Perhaps the CIOs' were overconfident about the capabilities of their departments and staffs.

Table 2. Current IS Situation

\begin{tabular}{lc}
\multicolumn{1}{c}{ IS Issues } & $\begin{array}{c}\text { Average } \\
\text { Rating* }\end{array}$ \\
\hline IS Department's Capability & 4.3 \\
Developing IS Skill Set & 4.3 \\
Managing Legacy Systems & 4.3 \\
Managing Communications Network & 4.2 \\
IT Budget & 4.1 \\
User Satisfaction with IS & 4.0 \\
IS Organization's Structure & 3.9 \\
IS Department's Delivery & 3.8 \\
Leadership Role of IS Within & 3.8 \\
Organization & 3.6 \\
Clear IS Governance & 3.0 \\
User Training \& Education & \\
\hline
\end{tabular}

$* 1=$ very poor, $5=$ very good

Another result that may be used as evidence for the overconfidence of the CIOs about their IT capability is the average rating of 3.0 for 'User Training \& Education.' A capable IS department having a wellqualified staff would be expected to provide better user education than what the results indicate. 
According to the literature, one of the problems that CIOs typically are faced with is insufficient IT budget, which can be the source of many other problems such as poor service quality and IT staff's skill set [14]. The average rating of 4.1 for 'IT Budget' by the CIOs indicates that they have reasonable IT budgets. As shown in Table 2, the average rating for IT governance is 3.6. Apparently, this is a challenge for the CIOs and they need to work on it.

Table 3 presents the third set of questions and the related ratings. The IT top managers were asked to rate the current major issues that are problematic in running their IS department, on the scale provided (1=very little, 5=very much.) As it can be seen in Table 3, all of the issues received low average ratings by the CIOs, indicating that none of the issues were problematic. These results are inconsistent with the findings in the literature. In particular, information systems' security, which is a major challenge for a majority of organizations [7], received a low average rating of 2.1. This means that IT security is not causing problems at all for the CIOs involved in the study. Perhaps these company officials are reluctant to reveal security problems, as indicated in the literature [4].

Table 3. Issues Causing Problems in IS Management

\begin{tabular}{lc}
\multicolumn{1}{c}{ IS Issues } & $\begin{array}{c}\text { Average } \\
\text { Rating* }\end{array}$ \\
\hline Top Management Commitment & 2.5 \\
Lack of IS Staff's Skill Set & 2.2 \\
Company-wide Support & 2.5 \\
Communication with Users & 2.7 \\
Intellectual Property Rights & 1.5 \\
Facilitating Organizational Learning & 2.6 \\
IS Security & 2.1 \\
Lack of time for Strategic Thinking & 2.7 \\
Coping with Change in Technology & 2.6 \\
\hline
\end{tabular}

$* 1=$ none, $5=$ very much

\section{CONCLUSIONS}

As mentioned earlier, the final results, shown above, were presented and discussed in class. Students were involved in the discussion and interpretation of the findings. In particular, all interview results that were inconsistent with the findings in the literature were pointed out and discussed at length. The objective of this process was to reinforce the active learning process.

In an MIS capstone course where students learn about information systems management issues and the role of the $\mathrm{CIO}$ a project that involves students interviewing CIOs face-to-face to learn what they do and discuss the results in class can facilitate students' active learning. In this particular course, students were guided through the several phases of the project and during the discussions in class. The emphasis in all phases was students' active involvement. Students were encouraged to share their learning experiences with each other (in group meetings and in class discussions) to develop better understanding of IS management issues and the role of CIOs in organizations.

At the end of the project, students provided feedback to the instructor. The following shows a summary of students' feedback:

- Discussing the paper and the list of issues with my group member helped me learn better.

- After interviewing the CIO, the IS management issues that I read in the textbook and the paper made a lot more sense to me.

- After talking with the CIO, the key IS management issues were no longer just theories, but real issues.

- The class discussions over the IS management issues were extremely helpful in understanding the subject, especially at the end, when the inconsistencies of the results were discussed.

- I got to know a CIO, which could help me find a job after graduation.

However, some students complained that the project was time consuming, although they worked in pairs and shared responsibilities.

From the instructor's point of view, through the entire process a significant amount of learning and understanding was very clear. The amount of students' learning was reflected in the tests also. To improve time and project management, perhaps a limit could be established for the course enrollment. A smaller number of students in class would require significantly less time and effort from the instructor considering all the work that needs to be put into such a project.

\section{REFERENCES}

1. Applegate, L. M., Austin, R. D. \& McFarlan, F. W. (2007). Corporate information strategy and 
management: Text and cases, $7^{\text {th }}$ Ed. New York, NY: McGraw-Hill Irwin.

2. Baetes, W. R. J.(1996). Some empirical evidence on IS strategy alignment in banking. Information \& Management, 30, 155-177.

3. Bashein, B. J. \& Markus, M. L.(1997). A credibility equation for IT specialists. Sloan Management Review, 38, 35-44.

4. Bhattacharyya et al.(2002). MET: An experimental system for malicious email tracking. New Security Paradigm Workshop, September 02, 23-26.

5. Booth, M. \& Philip, G. (2005). Information systems management: role of planning, alignment and leadership. Behavior \& Information Technology, 2I4(5), 391-404.

6. Boynton, A. C., Zmud, R. W., \& Jacob, G. C. (1994). The influence of IT management practice on IT use in large organizations. MIS Quarterly, 18, 299-316.

7. Broadbent, M. \& Weill, P. (1997). Management by maxim: How business and IT managers can create IT infrastructures. Sloan Management Review, 38, 77-92.

8. Earl, M. (1996). The risks of outsourcing IT. Sloan Management Review, Spring, 26-32.

9. Feeny, D. \& Willcocks, L. (1998). Core IS capabilities for exploiting information technology. Sloan Management Review, Spring, 9-21.

10. Gottschalk, P. Christensen, B. \& Watson, R.
(1997). Key issues in information systems management surveys: Methodological issues and choices in a Norwegian context. Scandinavian Journal of Information Systems, 9(2), 57-66.

11. Henderson, J. C. \& Thomas, J. B.(1992). Aligning business and information technology domains: Strategic planning in hospitals. Hospital and Health Services Administration, 37, 71-87.

12. McFarlan, Warren, F. Nolan, Richard, L. (1995). How to manage IT outsourcing alliance. Sloan Management Review, Winter, 9-23.

13. McNurlin, B. \& Sprague, R. (2006). Information systems management in practice, $7^{\text {th }}$ Ed. Upper Saddle River, New Jersey: Pearson/Prentice Hall

14. Powell, T. C. \& Dent-Micallef, A. (1997). Information technology as competitive advantage. The role of human business and technology resources. Strategic Management Journal, 18, 375-405.

15. Rockart, J. F., Earl, M. J., \& Ross, J. W. (1996). Eight imperatives for the new IT organization. Sloan Management Review, 38, 43-55.

16. Ward, J. \& Peppard, J. (1996). Reconciling the IT/business relationship - A troubled marriage in need of guidance. Journal of strategic Information Systems, 15, 37-65.

17. Willcocks, L. (1992). IT evaluation: Managing the catch-22. European Management Journal, 10, 220-229. 